\title{
Western blot detection of infectious bursal disease virus infection
}

S.R.F.G. Pereira, C.E.P.F.Travassos,

A. Huguenim, A.C.C. Guimarães,

A.G. Silva and

M.A.A.M. Guimarães
Departamento de Virologia, Instituto de Microbiologia Prof. Paulo de Góes, Centro de Ciências da Saúde, Universidade Federal do Rio de Janeiro, Rio de Janeiro, RJ, Brasil

\section{Correspondence \\ S.R.F.G. Pereira \\ Departamento de Virologia \\ Instituto de Microbiologia \\ Prof. Paulo de Góes, Bloco I CCS, UFRJ \\ 21941-590 Rio de Janeiro, RJ \\ Brasil \\ Fax: (021) 560-8344 \\ Email: silviagp@esquadro.com.br \\ Research supported by CAPES, CNPq and Fundação Banco do Brasil.}

Received June 14, 1996 Accepted January 12, 1998

\section{Abstract}

In order to evaluate the use of a Western blot methodology for the diagnosis of infectious bursal disease virus (IBDV) infection, chickens were experimentally infected with IBDV strains and tested for the presence of viral antigens and antibodies by a blocking Western blot test (bWB). The viral proteins obtained from the bursa of Fabricius

Key words - Western blot - IBDV infection

- Chicken (BF) were transferred to a nitrocellulose membrane after sodium dodecyl sulfate-polyacrylamide gel electrophoresis (SDS-PAGE), and the chicken sera obtained by heart puncture were used for the detection of these proteins. In order to eliminate nonspecific reactions, we used a rabbit anti-chicken serum (blocking tool). By the use of the bWB test, two distinct viral proteins of 43-kDa (VP2) and 32-kDa (VP3) were detected. We suggest the use of this methodology for the detection of IBDV infection in animals suspected of having IBDV reinfection and a chronic subclinical form of the disease. With the use of the rabbit anti-chicken sera for blocking, this method is practical, sensitive and less time consuming.

Infectious bursal disease viruses (IBDV) are economically important pathogens affecting the poultry industry worldwide. They may cause a highly contagious subclinical disease in young chickens characterized by severe immunodeficiency that leads to vaccination failure and opportunistic infections (1).

IBDV are members of the Birnaviridae family and Birnavirus genus. The family consists of non-enveloped animal viruses of about $60 \mathrm{~nm}$ in diameter with a single capsid structure of icosahedral symmetry having 92 capsomeres. The genome consists of two segments (A and B) of linear double-stranded RNA with a total molecular weight of $4.8 \mathrm{x}$
$10^{6}$. The viruses have four major structural proteins, including a transcriptase. Replication and assembly take place in the cytoplasm, and virus release occurs via cell destruction (2).

IBDV genome segment A $(3.2 \mathrm{~kb})$ encodes a 110-kDa precursor polyprotein which gives origin to VP2 (a neutralizing antigen), VP3 (a group-specific antigen) and VP4 (a protease involved in processing VP1 from the precursor polyprotein) (3). IBDV genome segment B $(2.9 \mathrm{~kb})$ encodes a $90-\mathrm{kDa}$ protein termed VP1, the putative RNA polymerase (transcriptase) (4).

There are two recognized IBDV serotypes: serotype 1 (virulent) and serotype 2 
Table 1 - Analysis of IBDV infection by the blocking Western blot methodology.

A total of 28 chickens were inoculated with IBDV. Half of them were inoculated with the ST-C strain (virulent) and the other half with the LUK strain (live attenuated). Although chickens inoculated with the LUK strain did not show any clinical symptons, animals inoculated with the virulent standard-challenge strain (ST-C) developed signs of illness from the 3rd to the 7th day after inoculation (a). Analysis of IBDV infection by the blocking Western blot (bWB) showed the presence of viral proteins (VP2 and VP4) from the 6th to the 30th day after inoculation.

\begin{tabular}{lccc}
\hline Animals & $\begin{array}{c}\text { Days after } \\
\text { inoculation }\end{array}$ & $\begin{array}{c}\text { Presence of } \\
\text { symptoms }\end{array}$ & bWB \\
\hline $1-4$ & 6 & $+^{\mathrm{a}}$ & + \\
$5-8$ & 12 & - & + \\
$9-12$ & 15 & - & + \\
$13-16$ & 18 & - & + \\
$17-20$ & 21 & - & + \\
$21-24$ & 24 & - & + \\
$25-28$ & 30 & - & + \\
& & & +
\end{tabular}

(avirulent) $(5,6)$. Vaccination of breeder hens with live-attenuated serotype 1 IBDV strains protects their offspring against IBDV (7), although virulent serotype 1 IBDV strains have been isolated from vaccinated flocks worldwide (8).

The objective of the present study was to detect IBDV antigens (due to viral replication) and antibodies present in infected animals by using the same blocking Western blot test (bWB).

One-day-old chicks were randomly divided into three groups of 14 animals each. The groups were housed separately in Horsfall-type isolation units for maternal antibody elimination (7). Before IBDV inoculation, the birds were bled by brachial venopuncture, and their sera were tested for the presence of IBDV-neutralizing antibodies (9). Two groups of birds were inoculated by the intraocular route with $0.03 \mathrm{ml}$ of viral inoculum and the last group was used as uninfected controls. One of the infected groups was inoculated with $10^{6.0} \mathrm{EID}_{50} \mathrm{dml}$ (mean embryo infective dose) of the virulent standard-challenge strain (ST-C), kindly supplied by Dr. J.K. Rosenberger (University of Delaware, Newark). The other group was inoculated with $10^{6.2} \mathrm{CCID}_{50} / \mathrm{ml}$ (mean cell culture infective dose) of a live-attenuated Lukert strain (LUK) commonly used as a commercial vaccine (Salsbury Laboratories, Charles City, IA). These two different IBDV strains were employed because, while the virulent strain causes a severe clinical disease, the vaccine strain causes a subclinical viral infection. At the 6th, 12th, 15th, 18th, 21st, 24th and 30th days after inoculation (a.i.), two birds of each group were bled by heart puncture until death, and blood and the bursa of Fabricius (BF) were asseptically collected. Serum and BF cell membrane suspension samples were obtained and stored at $-20^{\circ} \mathrm{C}$ (Table 1).

For the detection of viruses the $\mathrm{BF}$ were washed in 0.1 M PBS, pH 7.2, and the cells were ruptured with a Ten Broeck homogenizer. Cell lysates were centrifuged at 2,000 $g$ for $10 \mathrm{~min}$ and the pellets were treated with a detergent buffer (10 mM Tris-HCl, $\mathrm{pH} 7.0$, $500 \mathrm{mM}$ sucrose, $5 \mathrm{mM} \mathrm{MgCl}_{2}, 0.2 \mathrm{mM}$ EDTA, $1 \%$ Triton X-100 and $2 \mathrm{mM}$ PMSF) and a solubilization buffer $(0.5 \mathrm{M}$ Tris- $\mathrm{HCl}$, pH 6.8, 5\% glycerol, 2.5\% 2-mercaptoethanol, $0.001 \%$ bromophenol blue and $10 \%$ SDS) before SDS-polyacrylamide gel electrophoresis (SDS-PAGE) in a discontinuous system, as described by Laemmli (10). After SDS-PAGE, the proteins in the gel were transferred to a nitrocellulose membrane as described by Towbin et al. (11). For bWB detection of the IBDV proteins present in the nitrocellulose membrane, sera from the infected and uninfected chickens collected on the 6th, 12th, 15th, 18th, 21st, 24th and 30th days a.i. were used. To eliminate nonspecific reactions during the first step of the bWB reaction, the membranes were blocked with rabbit immune serum obtained by intramuscular inoculation of the rabbits with a BF cell membrane suspension from normal chickens. The blocked strips were then incu- 
bated with the animal sera and finally with the conjugate (anti-chicken serum conjugated with a peroxidase enzyme). The reaction was developed with 4-chloro-1-naphthol as substrate.

Chickens infected with the virulent IBDV strain developed clinical signs of illness from the 3 rd to the 7 th day a.i. These signs were ruffled feathers, trembling, depression, anorexia, watery diarrhea, and prostration, in agreement with the findings reported by Okoye (12). On the other hand, chickens infected with the vaccine strain did not develop any clinical signs of IBDV infection. The analysis of IBDV infection by the bWB test showed that both groups (infected with virulent and vaccine strains) had the same IBDV proteins and antibodies (Figure 1, lanes 4 and 5). IBVD VP2 and VP3 were detected in both groups of chickens (infected with the virulent ST-C and the vaccine LUK strain), being more evident on the 15 th day a.i., and not detected before the 6th day a.i. The detection of IBDV antibody from the 6th to the 30th day a.i. by bWB shows that the sensitivity of the test was satisfactory. Others have reported the detection of IBDV antibody from the 6th day a.i. onward using ELISA, immunofluorescence and agar gel diffusion tests $(12,13)$.

The use of a rabbit anti-chicken BF serum (blocking tool) eliminated nonspecific reactions (Figure 1, lanes 1,2 and 3) due to autoantibodies that are commonly detected in chicken serum infected by IBDV and Marek's disease virus (14-19), which impair the interpretation of the test. However, the blocking step did not eliminate two proteins of high molecular weight which were not related to the virus but were present even in the control group (Figure 1, lanes 1 to 6). Although we do not have any explanation about the origin of these two proteins, they did not interfere with the interpretation of

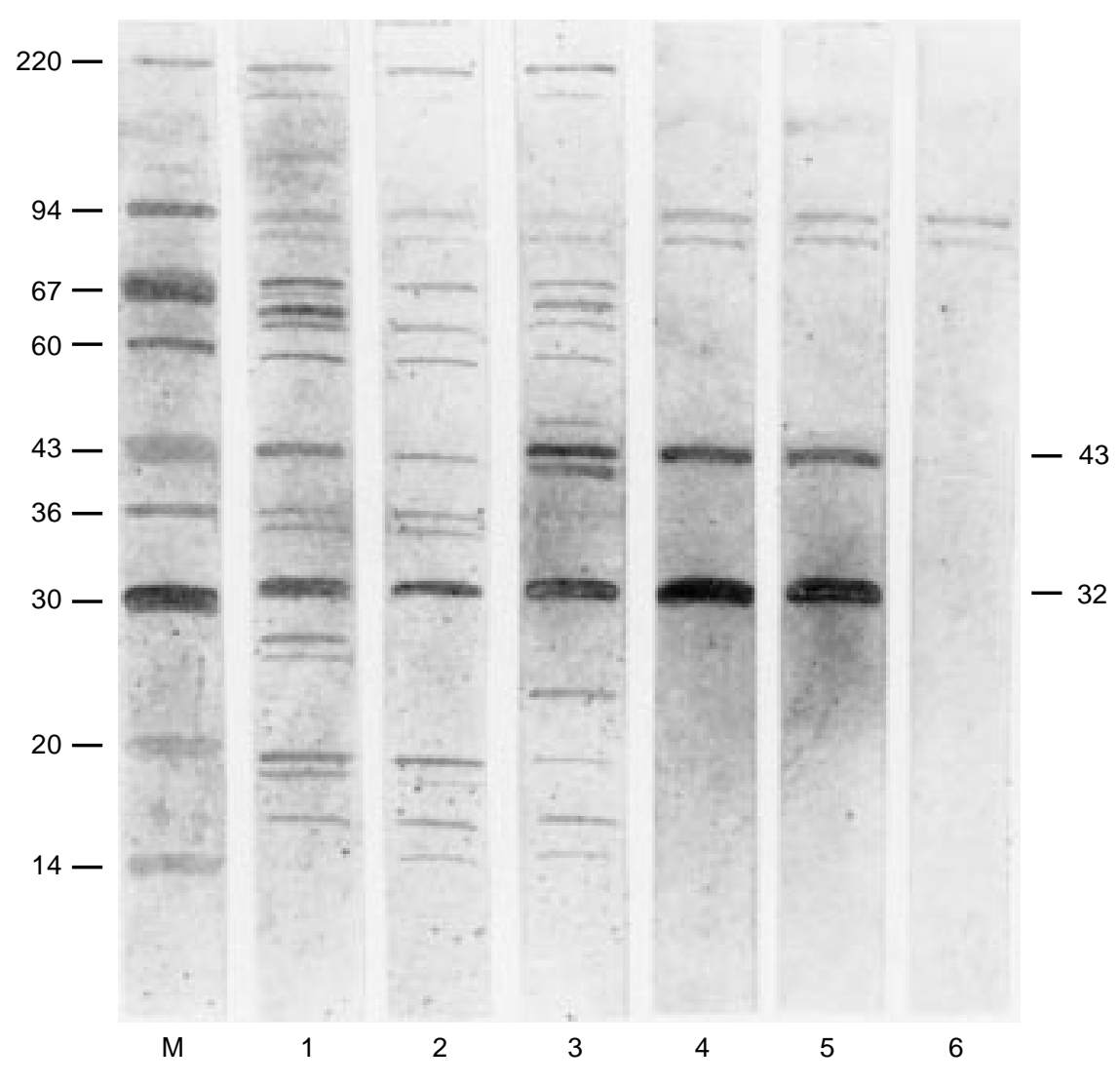

Figure 1 - Blocking Western blot analysis of infectious bursal disease virus (IBDV) infections of chickens on the 15th day a.i. Lanes 1, 2, 3: Western blot without blocking: chickens infected with the ST-C strain (lane 1), chickens infected with the LUK strain (lane 2), and uninfected control chickens (lane 3). Autoantibody reactivity and several proteins for infected chicken BF cell membranes (lanes 1 and 2), and also for uninfected chicken BF cell membranes (lane 3) can be observed. Lanes 4, 5, 6: Western blot with blocking: chickens infected with the ST-C strain (lane 4), chickens infected with the LUK strain (lane 5), and uninfected chickens (lane $6)$. The results show a 43-kDa (VP2) and a 32-kDa (VP3) IBDV-encoded protein and IBDV-specific antibody reactivity in lanes 4 and 5 . Two proteins of high molecular weight and not related to the virus were also observed in lanes 1 to 6 , possibly due to remaining autoantibodies. $M$, Molecular weight markers (BioRad, Richmond, CA). 
the results.

The diagnosis of IBDV infection can be made by detection of the virus or of the antibodies produced in response to viral infection. However, only the detection of the viruses or their constituents (viral proteins or viral genome) characterizes reinfection or a chronic subclinical IBDV infection because generally in these cases there is no serum conversion or the production of specific IgM. Thus, at the present time, the veterinary laboratories use virus isolation, histopathology and agar gel diffusion for routine diagnosis of IBDV infection. Other methodologies such as ELISA and WB can be used and are highly sensitive when compared to other tests for detection of viral protein. However, these two diagnostic methodologies require the employment of monoclonal antibodies (which are not available commercially) to eliminate nonspecific reactions. In our experiments the modification of the WB methodology (20) by the use of a blocking step eliminated the need for monoclonal antibodies and viral protein purification, turning the test less costly.

We suggest that this bWB could become an effective tool for the diagnosis of IBDV infections even in subclinical forms, helping to control these pathogens and consequently reducing the economic losses caused by subclinical IBDV infection in the poultry industry.

\section{Acknowledgments}

We would like to thank Prof. Ary Moreira de Souza for excellent technical assistance and stimulating discussions, and Prof. Allen Norton Hagler and Prof. Solange Marinho for critically reviewing this manuscript.

\section{References}

1. Hirai K \& Calnek BW (1979). In vitro replication on infectious bursal disease virus in established lymphoid cell lines and chicken B lymphocytes. Infection and Immunity, 25: 964-970.

2. Pereira HG (1989). Birnaviridae. In: Porterfield JS (Editor), Andrewes' Viruses of Vertebrates. 5th edn. Baillière Tindall, London, 11-17.

3. Azad AA, Jagadish MN, Brown MA \& Hudson $P$ (1987). Deletion mapping in Escherichia coli of the large genomic segment of a birnavirus. Virology, 161: 145-152.

4. Morgan MM, Macreadie IG, Harley VR, Hudson PJ \& Azad AA (1988). Sequence of the small double-stranded RNA genomic segment of infectious bursal disease virus and its deduced $90-k D a$ product. $\mathrm{Vi}$ rology, 163: 240-242.

5. Becht H, Müller H \& Müller HK (1988). Comparative studies on structural and antigenic properties of two serotypes of infectious bursal disease virus. Journal of General Virology, 69: 631-640.

6. Ismail NM, Saif YM \& Moorhead PD (1988). Lack of pathogenicity of five serotype 2 infectious bursal disease viruses. Avian Diseases, 32: 757-759.

7. Wood GH, Muskett JC \& Thornton DH (1981). The interaction of live vaccine and maternal antibody in protection against infectious bursal disease. Avian Pathology, 10: 365-373.

8. Craft DW, Brown J \& Lukert PD (1990). Effects of standard and variant strains of infectious bursal disease virus on infections of chickens. American Journal of Veterinary Research, 51:1192-1197.

9. Skeeles JK, Lukert PD, De Buysscher EV, Fletcher OJ \& Brown J (1979). Infectious bursal disease viral infections. I. Complement and virus-neutralizing antibody response following infection of susceptible chickens. Avian Diseases, 23: 95-106.

10. Laemmli UK (1970). Cleavage of structural proteins during the assembly of the head of bacteriophage T4. Nature, 227: 680-685.

11. Towbin H, Staeheflin T \& Gordon J (1979). Electrophoretic transfer of proteins from polyacrylamide gels to nitrocellulose sheets. Proceedings of the National Academy of Sciences, USA, 76: 4350-4354.

12. Okoye JOA (1984). Infectious bursal disease of chickens. Veterinary Bulletin, 54: 425-436.

13. McFerran JB \& McNulty MS (1981). Modern diagnostic methods in practice: aids to diagnosis of virological diseases. British Veterinary Journal, 137: 455-463.

14. Pereira SRFG, Travassos CEPF, Gusmão NP, Alves JB, Machado RD \& Silva AG
(1996). Infectious bursal disease of chickens: presence of autoantibodies. Journal of the Brazilian Society for Microbiology (in press).

15. Ley DH \& Yamamoto R (1979). Immune complex involvement in the pathogenesis of infectious bursal disease virus in chicks. Avian Diseases, 23: 219-224.

16. Kaul L \& Pradhan HK (1991). Immunopathology of Marek's disease in quails: presence of antinuclear antibody and immune complex. Veterinary Immunology and Immunopathology, 28: 89-96.

17. Albini B \& Wick G (1973). The influence of thymectomy on the development of erythrocyte-specific anti-nuclear factors in obese strain (OS) and normal White Leghorn chickens. Immunology, 24: 545-549.

18. Aldair BM \& Calvert VM (1980). Demonstration of anti-nuclear antibodies in fowl sera by immunofluorescence. Avian $\mathrm{Pa}$ thology, 9: 377-383.

19. Avrameas $S$, Dighiero G, Lymbery $P$ \& Guilber B (1983). Studies on natural antibodies and autoantibodies. Annals of Immunology, 134D: 103-113.

20. Fahey KJ, O'Donnel IJ \& Azad AA (1985). Characterization by Western blotting of the immunogens of infectious bursal disease virus. Journal of General Virology, 66: 1479-1488. 